\title{
Hearing the Sound of the Wave: What Impedes One's Ability to Foresee Innovations?
}

\author{
Vladimir Milovidov a;b \\ Department Head; and Head of the Centre for Prospective Studies, vladimir.milovidov@riss.ru \\ ${ }^{a}$ MGIMO University, 76, Prospect Vernadskogo, Moscow 119454, Russian Federation \\ ${ }^{\mathrm{b}}$ Russian Institute for Strategic Studies, 15B, Flotskaya str., Moscow 123413, Russian Federation
}

\begin{abstract}
$\mathrm{T}$ his paper offers a broad view on foreseeing innovation, which is not limited solely to early detection at the micro level. The author defines innovations as ongoing processes of changes in the various fields of social and economic life, which result from human creative activity. Noting that innovation is an uncertain, relatively chaotic, and disordered process characterized by inherent risks, the author aims to define the most general and universal barriers impeding one's ability to recognize the signs of future innovation and to anticipate their consequences. Considering examples of "disruptive innovation" in the technological, social, political, and economic spheres of life, the author sees these innovations as arising from certain condition and events, not as simple random occurrences. Most of them are effects of particular causes. However, these

causes are often hidden within events that are difficult to observe and phenomena encapsulated in weak signals. The inability to detect and recognize such pre-emerging warnings of upcoming innovations may be attributed to the massive amount of information and noise flooding today's world. This problem is exacerbated by the lack of knowledge, techniques, and experience for dealing with huge amounts of information, the lack of the required skills, and, finally, by human cognitive biases. Faced with this deluge of misinformation, any person can eventually be misled and make mistakes. This paper posits that, in order to mitigate such risks, an individual must avoid the three cognitive biases: the symmetry of delusions, aggressive neglect, and the curse of knowledge. These cognitive biases are the barriers to foreseeing innovation.
\end{abstract}

Keywords: disruptive innovations; emerging innovations; exponentially scalable events; proactive innovation management; big data; "symmetry of delusions"; "aggressive neglect"; "curse of knowledge".

Article type: research paper
Citation: Milovidov V. (2018) Hearing the Sound of the Wave: What Impedes One's Ability to Foresee Innovations? Foresight and STI Governance, vol. 12, no 1, pp. 88-97. DOI: 10.17323/2500-2597.2018.1.88.97 
$\mathrm{T}$ The current literature on management and technological development offers numerous definitions of innovation, with varying nuances and emphases (see, e.g.: [Schumpeter, 1942; Drucker, 1985; Damanpour, Schneider, 2006; Gopalakrishnan, Damanpour, 1997]). However, they all share concepts such as development, change, and transformation. Depending on the specific context, transformation and change may remain local, i.e. those taking place at the micro-level, or those that turn into major shifts in various spheres of human activities disrupting the established practices and customary methods. Innovative transformations can only be foreseen by considering individual changes occurring at the micro-level in the scope of a broader context of technological, organizational, marketing, legal, cultural, consumer-related, and other changes inherent to the development of any society. Fostering an innovative culture requires adopting a broad approach to perceiving the world and its development, including newly created and updated knowledge in a wide range of domains.

Practical experience of managing innovation-based development shows that limiting the perception of innovation to solely the local level and ignoring the diversity of available data hinder an adequate assessment of the various aspects of specific promising innovations, the key risks associated with innovative projects, their potential scale, and the timely discovery of alternative solutions. This paper builds upon the ideas and arguments suggested in the previously published study of the role of information in the innovative process, including the management and implementation of innovative projects and dealing with uncertainty and information asymmetry over the course of decision-making [Milovidov, 2015a, 2015b].

The role of information in the innovation process can be analyzed in the framework of either mainstream or evolutionary economics [Castellacci, 2008]. In the first case, an emphasis is placed upon finding the optimal balance for distributing information between participants of the innovation process and identifying information asymmetry and uncertainty. The second approach focuses on collecting and processing data to accumulate tacit and implicit knowledge and competences, which knowledge management theory places at the top of the data-information-knowledge-wisdom pyramid (DIKW) (see, e.g., [Cleveland, 1982; Erickson, Rothberg, 2014]). Both these approaches are based on peoples' ability to identify important information in the data flow, distinguish between significant and irrelevant facts, filter out information noise, analyze signals, and minimize the risk of making the incorrect innovation and management decisions. Another aspect is related to barriers and obstacles hindering the development and practical application of information processing abilities. What is it that stops individuals from recognizing and analyzing important information, detecting barely perceptible signals of emerging new developments, foreseeing innovative changes, and assessing their scale and strategic direction?

To answer the above questions, we examine the results obtained in two research areas. The first area comprises uncertainty and risks associated with the development process (including innovation-based development), and issues such as determinate and random events and chaotic transformations. The disruptive innovation concept appears to be particularly productive in the scope of this area [Bower, Christensen, 1995; Christensen, 2003]. Similar aspects were studied in the context of climate change [Lorenz, 1972], the growth of financial markets [Taleb, 2007], and political processes [Frank et al. 2012]. The second area comprises a large body of studies devoted to the processing of information, data mining, development of text processing algorithms, signal interpretation, and big data. The language and communication vagueness theory [Russell, 1923] seems to play a key role in this domain, along with the fuzzy sets concept [Zadeh, 1965], which gave a powerful impulse to the development of unstructured data analysis, the recognition of patterns and differences in large data arrays, and artificial intelligence research [Kohl, 1969; Liu et al., 2000; Carvalho et al., 2003; Zhong, 2003; Ruiz et al, 2014].

The first section of the present paper analyzes the general indications of unexpected, obscure information signals and events that are potentially capable of radically changing society. The second section examines data processing principles that could help one foresee innovation and help reduce the level of uncertainty and randomness of events. The third section highlights the obstacles which hinder the foresight of innovations and reduce the ability to "pre-hear" them, to use a rare verb from Dahl's Dictionary. ${ }^{1}$ The ability to perceive emerging but barely detectible changes is a key skill not only for professionals, but for everyone open to new developments.

\section{Disruptive Innovations: a Flock of Black Swans}

Major unpredictable changes in the external environment are frequently caused by obscure factors, which are impossible to foresee. The fear of sudden social and natural calamities caused by a chain of incomprehensible events has been disturbing humanity for centuries and is aptly reflected in our mythological, literary, and philosophical heritage. Very small things turning into something huge is a natural trait of our world, and many mind-boggling transformations were caused by people's economic or social activities, specific actions, and exploits.

Numerous scientists have tried to conceptualize the exponential transformation of initially weak impulses. More productive approaches to studying these processes were suggested in the mid- $20^{\text {th }}$ century, such as the "butterfly effect" [Lorenz, 1972], "disruptive innovations" [Christensen, 2003], "black swans" [Taleb, 2007], and "femtorisks" [Frank et al., 2012]. These metaphors are now widely used to describe unpredictable radical changes and major events. Before taking a closer look at such processes, we consider several examples from the technological domain which provide rich food for making generalizations and conclusions.

\footnotetext{
To use a rare verb from Dahl's Dictionary. Available at: https://dic.academic.ru/dic.nsf/enc2p/332542, accessed 26.01.2017.
} 

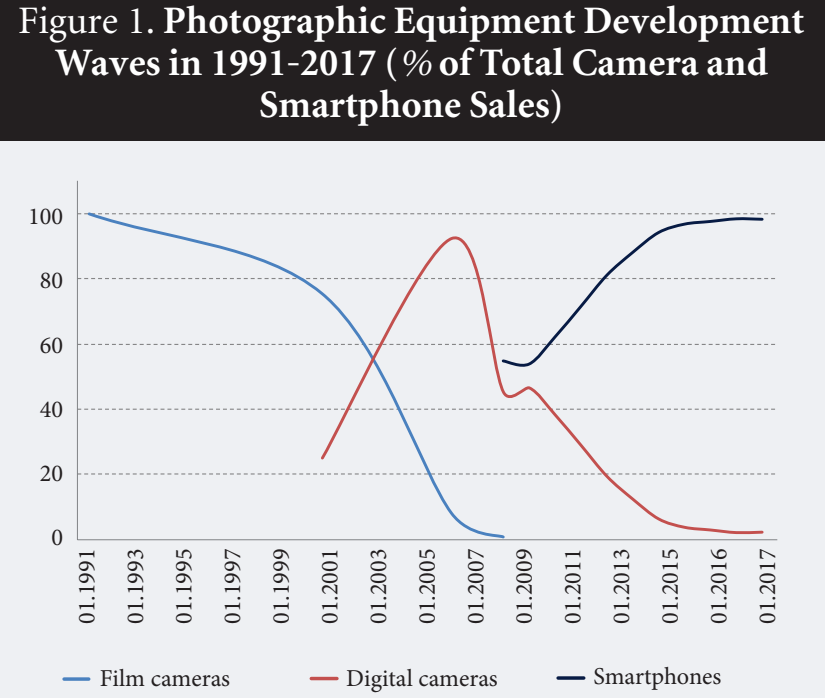

Source: composed by the author based on CIPA and Statista data.
Figure 2. Production of Conventional (the left scale) and Shale (the right scale) Oil in the US in 2000 - October, 2017 ( $\%$ of the Total Output)

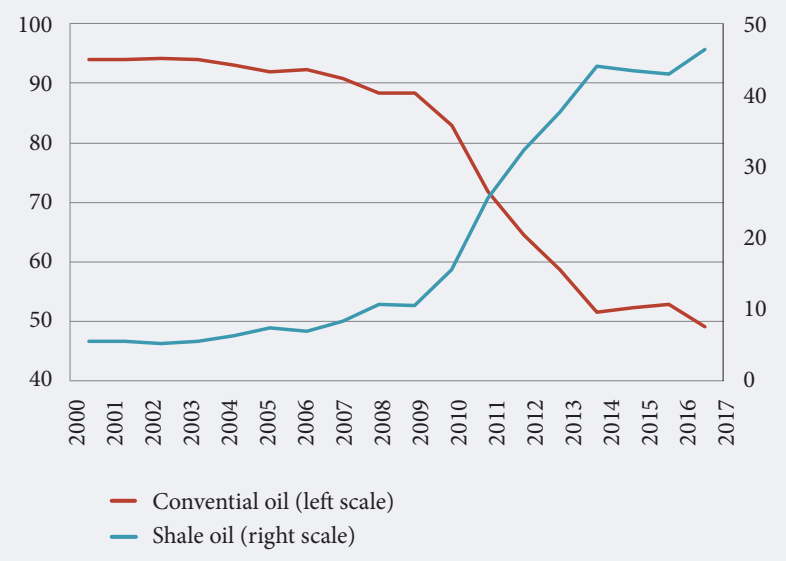

Source: composed by the author based on the US EIA data.

Figure 1 illustrates the development of photographic equipment. In the 1940s-1950s, photography was becoming increasingly popular around the world, while the hardware was becoming increasingly more affordable. Between 1951 and 1997, sales of single-lens film cameras grew from 258,000 to 36.6 million units [CIPA, n.d.]. In 1999, the digital camera was launched onto the mass market, so film cameras' monopoly very rapidly ended. By 2005, their market share dropped below $8 \%$, compared with $92 \%$ for digital ones. Since 2007, when film camera sales ended completely, smartphones challenged the dominance of digital cameras. In 2010, sales of digital cameras peaked at 121.5 million units versus 304 million for smartphones (or $71 \%$ of the market). Although digital camera sales currently remain at the peak level for film cameras, i.e., at about 35-36 million units a year, their market share has dropped to a mere $2.4 \%$. According to the Statista web portal, smartphone sales are now approaching 1.5 billion units. $^{2}$

Another example is the US shale oil production technologies. As in the previous case, we can see the same technology waves and comparable proliferation rates (Figure 2). The only difference is the rate of new technologies' maturing: digital photography took a somewhat longer time to arrive than the hydraulic fracturing of oil strata.

Similar innovation waves were observed in the social sphere as well, although they are much harder to identify and visualize than technology-related ones. The development of advanced internet technologies and search engines significantly increases the opportunities for detecting trends and popularizing innovations, both technological and socio-political. Statistics of search queries 'best smartphone camera, 'oil shale fracking', and 'Brexit' (Figure 3) show that these have become more popular among internet users.

Different growth rates of interest in innovations of various kinds are worthy of note. Users' interest in the best smartphone camera grew gradually and cumulatively, in line with the increased supply. The number of such queries peaked when the total supply of smartphones had reached 1 billion units. The number of oil fracking-related queries grew at a much more explosive rate: in 2013-2014, the topic's popularity literally skyrocketed. The peak level in 2014 coincided with the record daily US shale oil output - approximately 4.8 million out of the total 8.2 million barrels, according to the US Energy Information Administration (EIA). ${ }^{3}$ The outcome of the British referendum on leaving the EU also led to an exploding information bomb: internet users' interest peaked in a matter of days, and then faded quickly.

A declining interest in a topic, however, does not imply that the relevant innovations became less important. All the above innovations had significant long-term consequences. The wide use of smartphones contributed to the further 'democratization' of photography, increased popularity of 'selfies' and of social networks offering extended opportunities for posting photographs (such as Instagram, Snapchat, etc.). Greater use of smartphones also led to the development of specialized smartphone accessories, mobile applications, and software for processing smartphone-taken pictures. Besides the social effects and the emergence of new communication formats, the move from the camera to the smartphone significantly affected the photographic and mobile equipment industry. Increased shale oil production had significant consequences in a wider range of industries and spheres of activity. First, it promoted the development of oil production technologies and reduced related costs, but it also changed the way of life in several US regions, contributed to the emergence of new supporting industries, caused structural changes in global energy markets, and led to major economic, social, and political shifts in many countries. It would be harder to assess the chain of

2 Available at: https://www.statista.com/statistics/263441/global-smartphone-shipments-forecast/, accessed 04.01.2017.

3 Available at: https://www.eia.gov/energy_in_brief/article/shale_in_the_united_states.cfm, accessed 15.02.2016. 


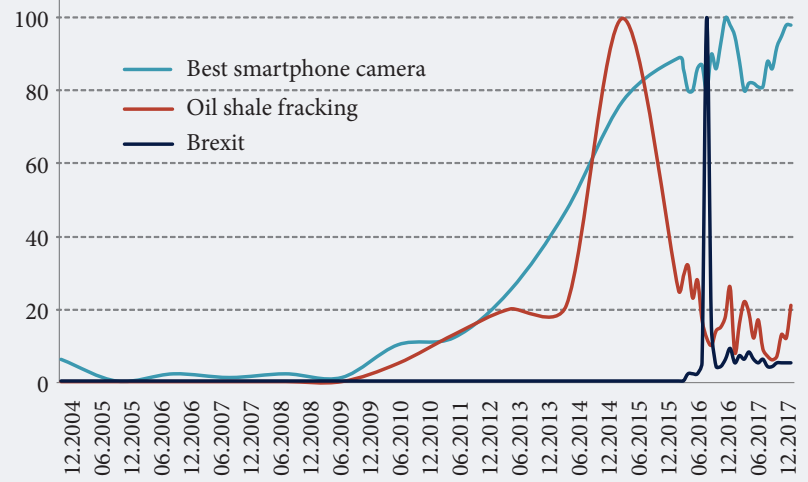

Note: in this and subsequent figures, the vertical axis measures the interest in the topic (the score of 100 denotes the highest number of relevant search queries submitted in a particular region within a specific period of time, 50 represents a $50 \%$ lower value, and $0-$ no more than $1 \%$ of the highest level).

Source: composed by the author based on the Google Trends data.

Brexit consequences at this stage, but it may germinate seeds of future radical geopolitical, economic, and social transformations.

The above considerations allow us to formulate several hypotheses:

H1. Innovations, or events that entail radical change and long-term consequences, may be either cumulative, impulsive, explosive, or sudden by nature.

H2. In terms of their impact, innovations' consequences may be either narrow, i.e., only affecting the area where the initial innovative impulse emerged (or related ones) or wide, i.e., affecting a potentially unlimited range of totally different spheres of human activities.

H3. Most innovations, whether socio-political or technological, turn out to be unpredictable for most consumers, and only attract mass attention when they become facts of everyday life.

H4. The exponential development of innovations normally takes place against a level background, and comprises a set of very small, insignificant events, discoveries, inventions, or other initiatives and actions seemingly appearing from nowhere, from ground zero.

H5. Any, even the most insignificant, innovations may have scalable consequences. Their concealed potential makes it much harder to detect trends and forecast the emergence of innovations, and therefore requires ongoing monitoring of innovative changes, the adoption of more efficient management practices, and the analysis of innovation-related data in a standardized, technological way.

The above hypotheses reflect, in a concentrated form, many years of research that has attempted to conceptualize the processes occurring in a wide range of domains. The novelty of Table 1 below lies in presenting a structured summary of existing definitions of exponential processes, together with their more important characteristics: obscurity, unpredictability of the initial impulse, spontaneity, wide scope, cumulativeness, and scalability. Besides, the definitions proposed by various researchers are compared with the 'exponentially scalable event' category suggested by this paper.

\section{Table 1. Definitions of the Exponential Transformation of 'Weak Initial Impulses'}

\begin{tabular}{|c|c|c|c|c|c|c|c|c|}
\hline \multirow{2}{*}{ Process } & \multirow{2}{*}{ Definition } & \multicolumn{7}{|c|}{ Characteristics } \\
\hline & & $\mathrm{I}$ & II & III & IV & $\mathrm{V}$ & $\mathrm{VI}$ & VII \\
\hline $\begin{array}{l}\text { Butterfly effect [Bradbury, } \\
\text { 1975; Lorenz, 1972] }\end{array}$ & $\begin{array}{l}\text { A process triggered by an insignificant impulse } \\
\text { (event), which entails determinate, chaotic, random } \\
\text { transformations with large-scale consequences }\end{array}$ & + & + & + & - & - & + & + \\
\hline $\begin{array}{l}\text { Disruptive innovations } \\
\text { [Christensen, 2003] }\end{array}$ & $\begin{array}{l}\text { Innovations in areas such as technological development } \\
\text { and company operations, including finance, marketing, } \\
\text { management, and product range, which may lead to } \\
\text { significant changes in the balance of forces in the market, } \\
\text { including pushing out major players }\end{array}$ & + & + & - & + & + & - & + \\
\hline Black swan [Taleb, 2007] & An unpredictable event with major consequences & + & + & + & - & - & + & + \\
\hline $\begin{array}{l}\text { Femtorisks [Frank et al., } \\
\text { 2012] }\end{array}$ & $\begin{array}{l}\text { Small, barely discernible events with significant } \\
\text { consequences in the socio-political sphere }\end{array}$ & + & + & + & - & - & + & + \\
\hline $\begin{array}{l}\text { Exponentially scalable } \\
\text { events [Milovidov, } \\
\text { 2015a,b] }\end{array}$ & $\begin{array}{l}\text { Any event which may affect the environment where it } \\
\text { occurred, triggers other subsequent events, and starts off } \\
\text { a sequence of changes when each next (scalable) event } \\
\text { increases the effect of the previous one }\end{array}$ & + & + & + & + & + & + & + \\
\hline \multicolumn{9}{|c|}{$\begin{array}{l}\text { Legend: I - obscure initial impulse; II - unpredictable; III - spontaneous; IV - cumulative; V - narrow scope; VI - wide scope; VII - scalable. } \\
\text { Note: '+' means the relevant criterion is included in the definition, '-' means it is not. } \\
\text { Source: composed by the author. }\end{array}$} \\
\hline
\end{tabular}




\section{Principles of Detecting Emerging Innovations}

Exponential, chaotic, and unpredictable scaling of initial impulse events is one of the key factors of the overall uncertainty of socio-economic, political, and technological processes which accompany (and affect) the current stage of human development. At the starting point of the triggering impulse, it is very hard to predict exactly how the events will unfold, what consequences they will have, and how they will affect human activities when the effect of the impulse starts to fade and is replaced by the new factors it has engendered.

Is it possible to calculate and forecast all consequences of a specific cause? Is it possible to develop an efficient algorithm for exponential scaling of very insignificant, obscure events? So far, no theoretical approach has provided credible answers to these questions. The world remains unpredictable at the local level, while forecasts and predictions, even the most correct ones, are practically never accurate in their details, which are often crucial. Without pretending to provide exhaustive answers, we suggest here some methodological and logical solutions that would minimize the risks of missing important events capable of causing major changes in the future and would help one avoid having to face their unpredictable consequences. We formulate the key principles of detecting innovations, information signals and impulses, and foreseeing their causal relations with future events and changes.

Ongoing Monitoring of Current Innovations. Monitoring the flow of events means we can track the chronology of specific processes. This principle is literally embodied in the works by Plato and Plutarch (see, e.g.: [Plato, 1994; Plutarch, 2008]), where events and phenomena of the external world are sequentially numbered. The numbers are added, multiplied, divided, ranged in series, applied to create geometric figures and lines - all to reveal a sequence, a pattern, or an interconnection. The works of ancient historians and philosophers are dotted with numerical calculations, i.e., the authors not only enthusiastically practiced arithmetic but studied the surrounding world highlighting all the obscure links and combinations. Ongoing monitoring gives volume to information, which makes processing it easier.

Proactive Observation and the Prioritization of Events. At the core of any prognostic activity lies interested, active perception, a focused desire to uncover and detect hidden changes in the surrounding world. Such a view implies universality, a contentious, debatable nature of any statement - the principle which in the $20^{\text {th }}$ century was called 'falsificationism' [Popper, 2002], 'problematization', or 'the archaeology of knowledge' [Foucault, 1994]. Problematization is a scientific analysis technique based on refuting and finding errors and weaknesses in any hypothesis, claim, or concept. It is a way to question whether the object or phenomenon the subject is facing is indeed what it seems or claims to be. The problematization technique allows us to model individuals' behavior in uncertain situations by asking new questions and pointing out contradictions implied by, or following from, their actions [Milovidov, 2015b]. A proactive approach to problematization can verify the collected data and check its veracity.

Balance between the Causes and Effects of Events. The Danish philosopher Søren Kierkegaard noted: 'As to the cause and effect relationship, something isn't right there also if I'm not mistaken. Sometimes a huge cause has extremely insignificant effects, or even none at all, while a silly trifling cause may lead to colossal consequences.'[Kierkegaard, 2016]. The disproportionality baffles witnesses of unexpected, unpredictable consequences caused by small, insignificant events. However, those who try to establish an incorrectly understood causal proportionality frequently miss the extremely small intermediate transformations. A tacit, latent symmetry of causes and effects is hidden in the flow of exponential, scalable events.

Returning to the example of photographic technologies' development, the average growth of film camera sales between 1951 and the peak in 1997 was 792,000 units a year; the relevant value for digital cameras was in excess of 10 million units between 1999 and the peak in 2010; and for smartphones - more than 160 million units between 2007 and 2015. Thus, the proportion of sales growth rates was 1:13 for film and digital cameras, 1:16 for digital cameras and smartphones, and 1:207 for film cameras and smartphones. These figures indicate that, compared with the growth of film camera sales, the emergence and proliferation of smartphones is an unprecedented explosive impulse. Smartphones have overturned our existing ideas about photographic and mobile communications technology. Even half a century ago, such figures would have seemed totally impossible, while today the growth rate of the smartphone market does not appear extraordinary given the dissemination of other popular technologies. The rates of abandoning some technologies in favour of others also turn out to be comparable. With time, and with the accumulation of practical experience, our perception of the relative importance of various changes alters. New important events even out the scale of previous ones.

Figure 4 illustrates the frequency of search queries for three 'innovations': recent unusual and unexpected events, namely the crash of the Lehman Brothers bank, Brexit, and the election of Donald Trump. The peak scores for each of them reached 100, but if we overlay the curves we can see that each previous event was noticeably less popular than the following ones. The farther back an event, the less important it seems to be compared with the present-day scoops.

Establishing causal proportionality requires us to take the velocity factor into account, which affects the relative importance of events.

The Discernibility and Visibility of Events against the Overall Information Landscape. This principle is directly connected with the previous one as the identification of events requires long-term systemic observation, collecting data and facts, and an inclination (ability) to identify specific features, very small signs, and faults, i.e., everything that makes observation proactive, inquisitive, oriented towards checking and re-checking 


\section{Figure 4. Comparative Frequency Growth of Google Search Queries} on Popular Topics in 2008 - October, 2017 (scores)

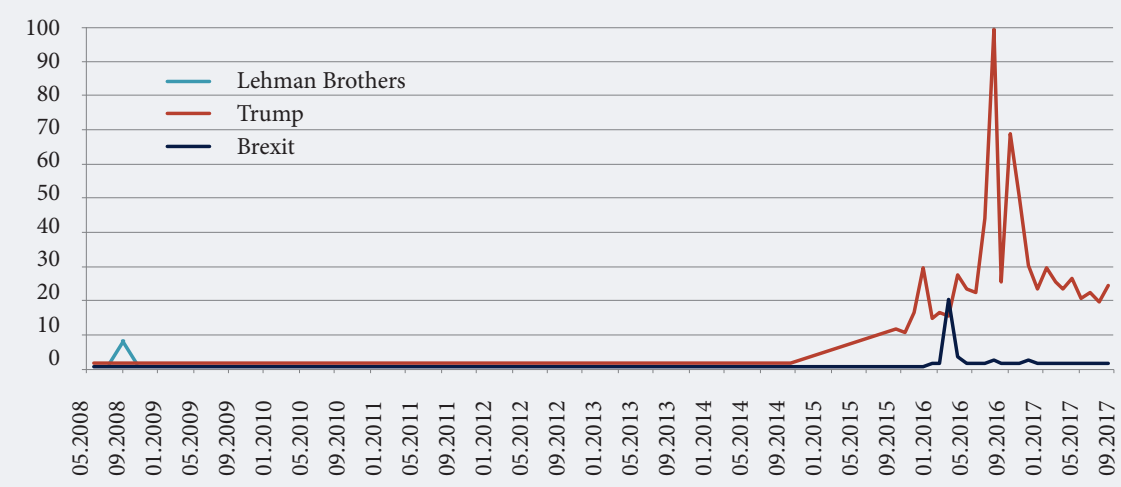

Source: composed by the author based on the Google Trends data.

the validity, verifying, or falsifying data. It is equally important to establish a reference point against which the changes will be checked and determine the scale of events to be tracked, the proportions of causes and effects, and the frequency and regularity of their occurrence. Accomplishing these objectives involves an ongoing proactive comparative analysis of events' variety.

Innovation theory uses the term 'innovation at the edge', which does not imply that such inventions are backward, amateurish, or inferior. The term is supposed to stress the alternative nature of cutting-edge (and typically very promising) innovative ideas compared with the academic mainstream. Such innovations, ideas, discoveries, and even vague insights fall outside the major areas of technological development where large $\mathrm{R} \& \mathrm{D}$ centers and leading companies concentrate most of their intellectual and financial resources. As early as March 2001, The Economist's Technology Quarterly review noted that: 'No question that technology is now driven by a centrifugal force, pushing power out from the centre to the edge.' [The Economist, 2001]. Small companies take the lead increasingly often in developing new technologies. A democratization of innovation is occurring, a division of control over the movement of ideas which 'cuts out whole layers of middle managers whose job had been to shuffle questions and answers between bosses and staff.'(Ibid.) However, such a decentralization of innovation activity participants (in the technological and also socio-political domain where new social groups, voluntary public associations, informal networks, and civic activists play an increasingly important role) make the task of detecting and tracking emerging innovations even more difficult. Following the 'beaten track' and adhering to established views and ingrained preferences results in a 'blindness' among individual high-ranking managers and experts, and even whole corporations. Max Bazerman in his book 'The Power of Noticing' noted: 'Finding the best solutions often requires dropping the proposed options and looking beyond the immediately obvious.' [Bazerman, 2014].

Most disruptive technologies that really revolutionize the technological structure and ways of life emerge outside the mainstream, or at its 'edge.' Such innovations are discernible: when they emerge, they clearly stand out among those widely applied in society. However, many companies lack the resources and consistency required to detect the difference and, more importantly, to assess the prospects, scalability, and exponential proliferation of these innovations. For example, in 1975 Steven J. Sasson, the engineer at Eastman Kodak which for years dominated the film and printing services market, invented the first digital camera. In 1986, Kodak engineers presented the first megapixel camera. However, rigid adherence to the strategy focused on manufacturing 'chemical photography' equipment, mistakes made by the management, and ill-conceived corporate business deals resulted in the company losing leadership not only in the digital photography innovation but in its core business field as well, bringing it to the brink of bankruptcy [Chunka, 2012].

Similar examples can also be found in the social and political domains. For example, there were signals which allowed one, if not to predict, then at least not to rule out British citizens' 2016 vote to leave the EU, or Donald Trump's victory in the US presidential elections in 2016. If more attention was paid to the market situation and the growth of debt, the crisis of 2007-2008 might have been less surprising. The reasons for Enron's bankruptcy in 2001 and Lehman Brothers bank's bankruptcy in 2008 lay in their financial reports, open business deals, and decisions made by management, none of which were secret. The weak signals suggesting problems simply remained unnoticed at the right time. Analysts use dynamic processes, new facts, and published data as sources where they try to find patterns like the current state of affairs, while in fact they should search for differences.

Taken together, the above principles of detecting exponentially scalable events can serve as an algorithm for processing data inputs. In turn, any algorithm can, up to a point, be automated. Let us try to match these principles with the main components of the concept of Big Data, i.e., the so-called four Vs: volume, veracity, 
velocity, and variety. Because they are innovative themselves, Big Data technologies can serve as powerful tools for foreseeing a wide range of disruptive innovations.

\section{What Hinders Hearing the Sound of the Wave?}

'No one errs willingly' [Segvic, 2000] - this commonplace adage reflects everyone's sincere and natural desire to avoid making mistakes. Countless theoretical and practical studies analyze management errors and make recommendations on how to avoid these mistakes. However, faults are inevitable, so important events, disruptive innovations, and 'black swans' constantly test the experts' professionalism and crisis management skills.

There are two ways to approach the issue of discerning emerging change and innovations. The first approach looks at the issue from the point of view of management practices and organizational mechanisms employed by specific companies, including self-discipline, self-organization, and employees' individual responsibilities. The second approach focuses on individuals' psychological and emotional perception of reality, their reactions, and attitudes toward events. In some cases, the second approach can be more productive as efficient management practices and advanced information technologies do not provide an insurance against making mistakes. Often, accumulated knowledge, qualifications, and education inspire an illusory and dangerous feeling of infallibility.

Let us consider three kinds of distortions in individuals' cognitive biases: error of judgement, hindering the adequate perception and analysis of information inputs, and creating the conditions for perceiving the emerging change as accidental and unexpected. All these distortions result in people who are unable to recognize the hidden determinacy of events and detect signals which can be transformed into scalable consequences.

Symmetry of Delusions. A state of persistent false confidence evenly distributed throughout society or within certain social groups [Milovidov, 2013], the symmetry of delusions is quite hard to identify at a given moment in time as proving that specific opinions are wrong is difficult. Mass consciousness rejects the disproof of commonplace views and social expectations. The symmetry of delusions in most cases can only be revealed post factum, after the events which radically undermined the established beliefs have happened. There are numerous examples of illusions shared by society being utterly crushed, one being economic and financial crises. Such turmoil always comes unexpectedly; just the day before, economic agents see no reason to worry, and enjoy continued growth. Signs of a symmetry of delusions can be found in practically every financial crisis including the famous tulip fever of the $17^{\text {th }}$ century. The historian of the global financial system, Charles Kindleberger, sneered about this: 'What is really interesting is how the insiders and outsiders joined forces to ensure financial crises happened regularly, at least once a decade between 1551 and 1886, though according to the economic theory outsiders have to get some sense first.' [Kindleberger, 1993].

What else besides symmetry of delusions can explain the fact that market upheavals always happen unexpectedly? That was the case in Russia on the eve of the infamous default of 1998, or before the global crisis of 2007-2008; the same happens today when energy prices sharply drop or skyrocket, or the central banks raise the interest rate. The 'black swan' phenomenon described by Nassim Taleb [Taleb, 2007] is based on nothing else but symmetry of delusions. Symmetry of delusions is an inertial perception of reality, a tendency to fit the current events into the context of past ones, and to see the future as a projection of what is happening now. That is why most forecasts and predictions turn out to be wrong. Their dependency on previous events, or the 'allure of the known' [D'Souza, Renner, 2014], is too high, regardless of how true the 'known' actually is. Meanwhile, signals indicating a disruption of the current trends are often so disproportionally weak that they fail to attract any attention.

Symmetry of delusions is very common in business, administration, and science. Thomas Kuhn conceptualized the structure of scientific revolutions and introduced the concept of 'normal science' as science that is firmly based on previous achievements and remains in the scope of the current paradigm. In other words, 'normal science' according to Kuhn represents established views that are shared by the professional community, which provide the basis for further research [Kuhn, 1962]. A scientific revolution essentially amounts to a disruption of the paradigm - a leap in new knowledge creation. Individualism, critical thinking, proactivity, and scepticism regarding commonly shared ideas and attitudes help counter and resist the symmetry of delusions.

Aggressive Neglect. Aggressive neglect of information, facts, or phenomena is expressed as individuals' conscious refusal to accept something that does not match their views or understanding. The term 'aggressive neglect' was suggested by the ornithologists Sidney Ripley, George Hutchinson, and Robert McArthur in their 1959 papers on birds' behavior. The scientists noted a surprising phenomenon: that birds of the same species were so fiercely aggressive towards other bird species that sometimes they neglected hatching and nurturing their own young, i.e., the procreation function. In effect, the most aggressive birds were harming their own species [Ripley, 1959]. Taking Ripley's hypothesis further, Hutchinson and McArthur called the observed phenomenon 'aggressive neglect' - 'a bird neglecting its progeny while it behaves extremely aggressively towards another bird' [Hutchinson, MacArthur, 1959].

In the case of the 2016 US elections, opinion polls indicated Hillary Clinton had an obvious advantage over Donald Trump. The political establishment was not prepared to treat the Republican candidate seriously; even in his own party he was considered an upstart. The US elites' behavior resembled the aggressive neglect of signals and warnings that contradicted common beliefs or popular opinions. The consequences of this 


\section{Figure 5. Comparative Eynamics of \#Trump and \#Clinton Hashtags'} Popularity in 2016 (scores)

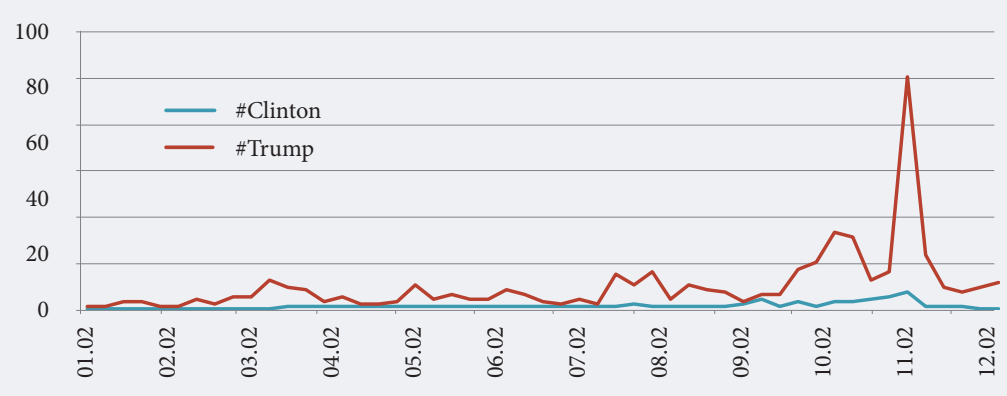

Source: composed by the author based on the Google Trends data.

situation turned out to be fatal for the Democratic candidate's team, and affected the result. Was it possible to hear the wave? Certainly, yes. Figure 5 clearly shows that throughout the year, up until election day, Trump's popularity in internet queries exceeded Clinton's. The average score of the Republican candidate's popularity during the whole period was 10 compared to 1 for the Democratic candidate. Most analysts preferred not to see these data, unlike their more observant colleagues. As early as 2004, the Indian innovator and entrepreneur Sanjeev Rai created the artificial intelligence system 'MogIA', which can process up to 20 million data points aggregated in social networks and other internet services, including search platforms. His system accurately predicted the results of the two most recent US election campaigns. In October 2016, a month before the latest US presidential election, Rai predicted Trump's victory based on the results produced by his system [Kharpal, 2016; Murnane, 2016].

Another example of aggressive neglect is the management of Kodak, who were unable to see the significance of the company's own engineers inventing the first digital camera. Later, Steven J. Sasson recalled that his invention was greeted by management with the words 'that's cute - but don't tell anyone about it.' [Deutsch, 2008] The growth of Trump's popularity leading to his largely unexpected triumph and Kodak's digital camera were 'innovations at the edge, which emerged outside mainstream thinking. The same can be said about the discovery of X-rays, which were initially perceived as an elaborate mystification [Kuhn, 2009]. There are numerous examples of aggressive neglect adversely affecting rational thinking, leading to neglecting facts and warnings and ultimately turning out to be destructive. Aggressive neglect multiplies the errors engendered by symmetry of delusions.

Curse of Knowledge. The term 'curse of knowledge' comprises overconfidence and overestimating one's own abilities, leading people to rely on their knowledge and experience so much that they cannot imagine possibly being wrong while exaggerating the probability of others' making a mistake. It was originally suggested in the scope of a survey of financial market players whose behavior was determined by the level of their knowledge. Colin Camerer and his colleagues discovered that most well-informed market players tended to discount the actions of their less knowledgeable counterparts. In effect, they totally disregarded them, relying exclusively on their own knowledge and ideas. That was frequently why strong players made mistakes and lost money: in certain situations, a lack of knowledge is much more preferable than its overabundance [Camerer et al., 1989].

The curse of knowledge certainly does not apply exclusively to financial markets. More generally, it can be compared with an inductive approach to a problem. In examining the core of the issue, a researcher tries to study every detail but at the same time loses their peripheral vision, i.e., the ability to take external aspects into account. The curse of knowledge frequently results from the desire to substantiate the old paradigm, the normal science; it is linked to the development of incremental technologies and major pressure groups' commitment to established values and opinions. First, people contaminated with the curse of knowledge are sure that they know exactly how the world works. Second, they are ready to defend their views, and third, they would resist any radical innovations that question their convictions. Ultimately, the curse of knowledge, along with symmetry of delusions and aggressive neglect, lead to errors. According to Jim Collins and Morten Hansen, arrogance borne by success is the first step towards a company's downfall [Collins, Hansen, 2011].

\section{Discussion}

Analyzing the reasons why people cannot see important, albeit obscure information signals, and take them into account when making decisions allows us to improve the overall approach to using information when managing innovative projects, designing strategic plans, development programs, and roadmaps, at both the micro- and macro-levels of public sector foresight activities. Attempting to do the following in several areas would help to accomplish this objective. 
Putting into place a holistic, adjustable information processing system, developing relevant algorithms and big data analysis technologies to minimize the impact of the subjectivity factor. This requires, for example, adopting legislation to review the norms hindering the efficient processing and productive use of information. Biased thinking and biased perception of signals and events would become worse for the wider the circle of active stakeholders in strategic planning and foresight because an increased number of stakeholders leads to the emergence of various groups, which might see other groups as rivals. Clashing points of view and competition between their proponents affect how information available to stakeholders is evaluated. At some stage, cooperation aimed at accumulating information and developing a common system of knowledge on particular issues may be replaced by defiance, trying to defend certainly false ideas that are shared by one's circle, and an aggressive neglect of other people's opinions. Accordingly, all stakeholders, regardless of their group membership, may become hostage to the curse of knowledge.

Standardization of corporate innovation management. We are still at the beginning of this path, although things are moving quite quickly. The European innovation management standards (CEN/TS 16555) ${ }^{4}$ already include organizational algorithms for collecting, processing, and analyzing data at all stages of innovation management. They imply exchanging information, documenting it at companies, and promoting cooperation between in-house and external experts and professionals specializing in applying the innovation management system for the purposes of creating, exchanging, and disseminating new knowledge (CEN/TS 16555-1 'Innovation Management. Part 1: Innovation Management System'). Strategic monitoring, or intelligence-related issues are regulated separately (CEN/TS 16555-2 'Innovation Management. Part 2: Strategic Intelligence Management'); here, the goal is to promote the development of prognostic competences, forecast innovation-related events, and identify information critically important for making strategic decisions. Strategic intelligence comprises collecting, processing, analyzing, and generating information and knowledge which would make a significant contribution at the more important innovation management stages (GOST 56273.1-2014/CEN/NS 16555-1:2013). Its principles are also described in the intellectual property management standard (CEN/TS 16555-4 'Innovation Management. Part 4: Intellectual Property Management').

In order to prevent cognitive bias, certain steps have already been taken by adopting the standards 'Managing innovation thinking' (CEN/TS 16555-4 'Innovation Management. Part 3: Innovation Thinking') and 'Managing collaboration' (CEN/TS 16555-5 'Innovation Management. Part 5: Collaboration Management'). The developers stress that innovative thinking and collaboration (essentially, external expert evaluation) are particularly important for making decisions in highly uncertain and risky situations. Their recommendations largely match the principles of working with information as described above, such as a proactive approach, causal proportionality, or discernibility of events, which help to minimize cognitive bias. No standard can completely eliminate biases of this kind, but it does not mean that this goal is unrealistic by definition, or that any formalization of innovation management would be inefficient by default. Individuals' perception of information signals will always remain arbitrary up to a point, but standardizing procedures for their interpretation and application, and building relevant competences would help to minimize the adverse effects of subjectivity factors on decision-making.

Managers and professionals responsible for, and specializing in, strategic planning and foresight should improve their skills required to manage and control their cognitive states and emotions, and suppress spontaneous impulses fraught with making mistakes. Ultimately, the success of overcoming cognitive biases depends on individuals themselves. They do not always realize they are being held captive by their illusions. There are no ready-made procedures for dealing with this issue; much depends on unconscious reactions, the overall cultural level, and experience. One must learn to avoid cognitive biases all the time, and nurture a culture of interested and careful observation. Without such skills, people today can be very susceptible to all sorts of ideas and suggestions, they may fall victim to informational noise that hides the actual essence of events, lose their connection with reality, and become hostage to external circumstances.

\section{References}

Bazerman M. (2014) The Power of Noticing: What the Best Leaders See, New York: Simon \& Schuster.

Bower J.L., Christensen C.M. (1995) Disruptive technologies: Catching the wave. Harvard Business Review, no 1, pp. 43-53. DOI: $10.1225 / 3510$.

Bradbury R. (1975) Short story collection, London: Harrap.

Camerer C., Loewenstein G., Weber M. (1989) The curse of knowledge in economic settings: An experimental analysis. The Journal of Political Economy, vol. 97, no 5, pp. 1232-1254. DOI: 10.1086/261651.

Carvalho D.R., Freitas A.A., Ebecken F.F. (2003) A critical review of rule surprisingness measures. Transactions on Information and Communications Technologies, vol. 29, pp. 545-555.

Castellacci F. (2008) Innovation and the competitiveness of industries: Comparing the mainstream and the evolutionary approaches. Technological Forecasting and Social Change, vol. 75, no 7, pp. 984-1006.

Christensen C.M. (2003) The Innovator's Dilemma, New York: Harper Business.

Chunka M. (2012) How Kodak Failed. Forbes, 18.01.2012. Available at: http://www.forbes.com/sites/ chunkamui/2012/01/18/how-kodak-failed/2/\#7f5029321a42, accessed 17.02.2017.

\footnotetext{
${ }^{4}$ Available at: https://standards.cen.eu/dyn/www/f?p=204:32:0::::FSP_ORG_ID,FSP_LANG_ID:671850,25\&cs=1C854451790B954 006838B674ED567E71, accessed 23.09.2017.
} 
CIPA (n.d.) CIPA Report, Tokyo: Camera and Imaging Products Association. Available at: http://www.cipa.jp/stats/ report_e.html, accessed 22.12.2016.

Cleveland H. (1982) Information as a resource. The Futurist, vol. 16, no 6, pp. 34-39.

Collins J., Hansen M. (2011) Great by Choice. Uncertainty, Chaos, and Luck - Why Some Thrive Despite Them All, New York: Harper Collins.

D'Souza S., Renner D. (2014) Not Knowing: The Art of Turning Uncertainty into Opportunity, London: LID Publishing.

Damanpour F., Schneider M. (2006) Phases of the adoption of innovation in organizations: Effects of environment, organization and top managers. British Journal of Management, vol. 17, pp. 215-236.

Deutsch C. (2008) At Kodak, Some Old Things are New Again. The New York Times, 02.05.2008. Available at: http:// www.nytimes.com/2008/05/02/technology/02kodak.html, accessed 14.03.2017.

Druker P. (1985) Innovation and Entrepreneurship. Practice and Principles, New York: HarperCollins.

Erickson S., Rothberg H. (2014) Big Data and Knowledge Management: Establishing a Conceptual Foundation. The Electronic Journal of Knowledge Management, vol. 12, no 2, pp. 108-116. Available at: http://www.ejkm.com/ volume12/issue2/p108, accessed 25.10.2016.

Foucault M. (1994) Ethics: Subjectivity and Truth, New York: New York Press.

Frank A., Goud Collins M., Clegg M., Dieckmann U., Kremenyuk V., Kryazhimskiy A., Linnerooth-Bayer J., Levin S., Lo A., Ramalingam B., Ramo J., Roy S., Saari D., Shtauber Z., Sigmund K., Tepperman J., Thurner S., Yiwei W., von Winterfeldt D. (2012) Security in the Age of Systemic Risk: Strategies, Tactics and Options for Dealing with Femtorisks and Beyond (Internal Report, IR-12-010), Laxenbourg: International Institute for Applied Systems Analysis.

Gopalakrishnan S., Damanpour F. (1997) A review of innovation research in economics, sociology and technology management. Omega: The International Journal of Management Science, vol. 25, no 1, pp. 15-28.

Hutchinson G.E., MacArthur R.H. (1959) Appendix. On the theoretical significance of aggressive neglect in interspecific competition. The American Naturalist, no 93 (869), pp. 133-134.

Kharpal A. (2016) Trump will win election and is more popular then Obama in 2008, AI system finds. CNBC, 28.10.2016. Available at: http://www.cnbc.com/2016/10/28/donald-trump-will-win-the-election-and-is-morepopular-than-obama-in-2008-ai-system-finds.html, accessed 14.03.2017.

Kierkegaard S. (2016) Dnevnik obol'stitelya. Aforizmy estetika [Diary of the seducer. Aphorisms of aesthetics], Moscow: "Kniga po Trebovaniyu" (in Russian).

Kindleberger C. (1993) A Financial History of Western Europe, New York, Oxford: Oxford University Press.

Kohl M. (1969) Bertran Russell on Vagueness. Australian Journal of Philosophy, vol. 47, no 1, pp. 1-11.

Kuhn T. (1962) The Structure of Scientific Revolutions, Chicago: University of Chicago Press.

Liu B., Hsu W., Chen S., Ma Y. (2000) Analyzing the subjective interestingness of association rules. IEEE Intelligent Systems and Their Applications, vol. 15, no 5, pp. 47-55. DOI: 10.1109/5254.889106.

Lorenz E. (1972) Predictability: Does the Flap of a Butterfly's Wings in Brazil Set Off a Tornado in Texas? (Paper presented at the 139th AAAS Meeting, 29.12.1972, Section on Environmental Sciences New Approaches to Global Weather: GARP (The Global Atmospheric Research Program)), Washington, D.C.: American Association for the Advancement of Science. Available at: http://eaps4.mit.edu/research/Lorenz/Butterfly_1972.pdf, accessed 01.12.2017.

Milovidov V. (2013) Asimmetriya informatsii ili "simmetriya zabluzhdenii"? [Asymmetry of Information or "Symmetry of Delusions"?]. Mirovaya ekonomika i mezhdunarodnye otnosheniya [World Economy and International Relations], no 3, pp. 45-53 (in Russian).

Milovidov V. (2015a) Proaktivnoe upravlenie innovatsiyami: sostavlenie karty znanii [Proactive innovation management: Knowledge mapping]. Neftyanoe khozyaistvo [Oil Industry], no 8, pp. 16-21.

Milovidov V. (2015b) Upravlenie riskami v usloviyakh asimmetrii informatsii: otlichai otlichimoe [Risk Management under Informational Asymmetry: To Differentiate Those Distinguishable]. Mirovaya ekonomika i mezhdunarodnye otnosheniya [World Economy and International Relations], no 8, pp. 14-24 (in Russian).

Murnane K. (2016) “Trump Wins!” Or AI May Have Just Had It's Dewey Moment. Forbes, 29.10.2016. Available at: $\quad$ http://www.forbes.com/sites/kevinmurnane/2016/10/29/trump-wins-or-ai-may-have-just-had-its-deweymoment/print/, accessed 23.12.2016.

Plato (1994) Sobranie sochinenii ( $v 4 t$.) [Collected works (in 4 volumes)], vol. 4, Moscow: Mysl' (in Russian).

Plutarkh (2008) Sochineniya [Works], Saint-Petersburgh: Saint-Petersburgh University (in Russian).

Popper K. (2002) The Logic of Science Discovery, London: Routledge.

Ripley S.D. (1959) Competition between sunbird and honeyeater species in the Moluccan islands. The American Naturalist, no 93 (869), pp. 127-132.

Ruiz M.D., Martin-Bautista M.J., Sanchez D., Vila V.-A., Delgado M. (2014) Anomaly detection using fuzzy association rules. International Journal of Electronic Security and Digital Forensics, vol. 6, no 1, pp. 25-37.

Russell B. (1923) Vagueness. The Australasian Journal of Psychology and Philosophy, no 1, pp. 84-92.

Schumpeter J.A. (1942) Capitalism, Socialism and Democracy, New York: Harper \& Row.

Segvic H. (2000) No one errs willingly: The meaning of Socratic intellectualism. Oxford Studies in Ancient Philosophy (ed. D. Sedley), vol. XIX (Winter 2000), Oxford: Oxford University Press, pp. 1-45. Available at: http://ancphil.lsa. umich.edu/-/downloads/osap/19-Segvic.pdf, accessed 19.06.2017.

Taleb N.N. (2007) The Black Swan: The Impact of the Highly Improbable, New York: Random House.

The Economist (2001) Innovation at the edge. The Economist. Technology Quarterly. Q1, 22.03.2001. Available at: http://www.economist.com/node/539606/print, accessed 01.12.2017.

Zadeh L.A. (1965) Fuzzy Sets. Information and Control, no 8, pp. 338-353.

Zong N. (2003) Peculiarity Oriented Multidatabase Mining. IEEE Transactions on Knowledge and Data Engineering, vol. 15 , no 4, pp. 952-960. 